\section{Another hole in ozone data?}

\section{Tokyo \& Washington}

ANOTHER gap in observations of the Earth's ozone layer may open up in the mid-1990s because of a decision by the Japanese government to delay the launch of an advanced Earth observation satellite.

Two weeks ago, Japan's Science and Technology Agency informed US and European partners that the launch of the Advanced Earth Observing Satellite (ADEOS) will be delayed one year, until early 1996. ADEOS will carry radio wave and optical sensors built by the US $\mathrm{Na}$ tional Aeronautics and Space Administration (NASA) and the Centre Nationale d'Etudes Spatiales (CNES) of France, including one of NASA's Total Ozone Mapping Spectrometers (TOMS).

A decision to drop the planned launch of the German satellite ATMOS has already opened up a yawning gap in the mid-1990s in data on chemical changes in

the ozone layer (Nature 355, 662; 1992). The TOMS detector on ADEOS, which will measure the total amount of ozone in the column beneath the satellite, will be the fourth in a series. Because the missions have a projected life of only two years, NASA officials are concerned that the one-year delay could open up another gap in ozone observations.

The decision to delay ADEOS came after the space agency failed to get the full budget it was requesting for the satellite in fiscal year 1992, which starts next month. An agency official says the chief reason for delay is technical difficulties in getting the many sensors on the ADEOS platform to work together. But the Japanese have told NASA that the delay was for budgetary reasons and because of an agreement with the Japanese fishing industry.

David Swinbanks \& Christopher Anderson

\title{
Solving a fishy problem
}

THE ability of fishermen to hold up the launch of Japan's rockets (see above) is just one example of their disproportionate political power in Japan.

When the National Space Development Agency (NASDA) established its launch site on the little island of Tanegashima off Kyushu, the southern main island of Japan, negotiations with local fishermen were a major hurdle. But with the help of a leading member of the ruling Liberal Democratic Party, an agreement was reached that provides the fishermen with $¥ 600$ million ( $\$ 4.6$ million) every year in "compensation' for damage caused to their tuna fisheries by rocket launches. Of course, nobody knows whether the launches cause any damage to the fisheries.

In return, NASDA is allowed to launch during two, two-month periods each in summer and winter. Because the nearby space centre of the Institute of Space and Astronautical Science must fit into the same window, NASDA is effectively limited to two launches a year. The ability of fishermen to hold the government to ransom stems from the political power of fishing cooperatives. For example, before work began on construction of a man-made island off Osaka to accommodate a new 24hour international airport, fishermen from nearby cooperatives were paid a total of over $¥ 40,000$ million ( $\$ 307$ million) before construction could proceed.

D.S.

\section{HIGH-ENERGY PHYSICS}

\section{Z not}

THE race to produce rare $\mathrm{Z}$ particles has turned into a blowout.

The big loser is the Stanford Linear Accelerator Center (SLAC), the US laboratory that had hoped to use a cheap and novel collider to beat its competitor, the Large Electron-Positron (LEP) collider at CERN, the European physics laboratory outside Geneva. It is now clear that such an approach has not worked.

Last month, at a meeting of an advisory panel to the US Department of Energy, SLAC reported that its new machine had produced only 1,600 “Znaughts" last year, of which just one-third were actually captured by a detector. During the same period LEP produced about a million of the particles. "It's no longer a race," concedes
William Kirk, SLAC's assistant director. SLAC researchers were never able to transcend their new machine's tricky beam geometry and technical malfunctions, he says. Worse yet, the one advantage over LEP that SLAC seemed to have - a polarized beam -- has not materialized. The polarized electron source that was installed a month ago did not work, and SLAC is now trying to design another. The replacement "better work out or it will be highly embarrassing," says Kirk.

That may be an understatement. With little on the long-term table but a controversial proposal for another new accelerator (see story page 97), SLAC is facing a future that contains virtually no worldclass physics. Christopher Anderson

\section{Small uncertainties}

WFLSH higher education has been thrown into confusion by the reorganization of funding arrangements for universities announced last year.

The surprise decisions that polytechnics would in future have the status of universities and that there would be a separate funding council for Wales as well as Scotland has provoked questions about future relationships between a handful of institutions. There is only one federal university and only one polytechnic (which hopes to become the University of Glamorgan).

One complication is that the polytechnic seems bent on resisting pressure to become the seventh constituent college of the federal university. Another is that some of the larger university colleges, notably Cardiff and Swansea (with $\mathbf{4 0}$ per cent and 22 per cent of the university's 20,000 students, respectively) hanker for separation.

In microcosm, Welsh uncertainties are those of British higher education at large. But they have been magnified by two developments: the decision that there should be a second funding council for Welsh further education, but with the same chief executive (Professor John Andrews of Aberystwyth); and the appointment last year of Professor Sir John Meurig Thomas as deputy pro-chancellor of the university, apparently with a brief to strengthen the federal structure.

The six colleges of the university (which include the Welsh National School of Medicine) at present deal separately with the Universities Funding Council (UFC) for the United Kingdom. Officials working on the new structure say that this direct relationship will continue, and that the new council will follow UK practice in the past few years by allocating funds on criteria linked with teaching (student numbers), research and graduate education. But the larger colleges fear the dilution of the research criterion.

The polytechnic, by contrast, behaves as if it can only benefit by remaining independent (having shaken off local authority control after the Education Act of 1986). Transmogrified from its status before the Second World War as a mining engineering college, it now has the equivalent of 6,000 full-time students, most following degree courses that often have a vocational slant.

The calculation seems to be that the polytechnic, with a smaller ratio of faculty members to students than most universities and with a substantial income from mostly commissioned research, cannot lose from the application of rules devised for universities. But inter-institutional politics may yet intervene, illustrating that British university planning now depends on second-guessing institutions not yet in existence.

John Maddox 